\title{
Histopathological Evaluation of Myometrial Lesions of Corpus Uterus-A Tertiary Care Hospital Based Study
}

\author{
Authors \\ Baishya Pakesh ${ }^{1}$, Hazarika K Ram ${ }^{1}$ \\ ${ }^{1}$ Department of Pathology, Assam Medical College \& hospital, Dibrugarh, Assam \\ Corresponding Author \\ Dr Pakesh Baishya \\ House no 46, Jatia, Kahilipara Road, Guwahati, Assam, India \\ Email:pragbaishya@gmail.com
}

\begin{abstract}
The aim of the study was to evaluate the distribution of various types of myometrial lesion (both neoplastic and non-neoplastic) in the hysterectomy and myomectomy specimens received in our institution. The pattern of occurrence of different myometrial lesions in relation to age, parity and mode of presentation and histopathological features of the myometrial lesions were also noted to find out any significance on this study.
\end{abstract}

Keywords-Leiomyoma, adenomyosis, menorrhagia, dysmenorrhoea.

\section{Introduction}

Most of the females visit hospitals due to gynaecological problems. In this part of our country gynaecological operation most commonly performed is hysterectomy and most of the corresponding pathological lesions lie in the uterine corpus.

Uterus is the most important female reproductive organ and it is under the influence of hormones. Anatomically it comprises of endometrium, myometrium and the perimetrium. Myometrium is composed of smooth muscles and give rise to variety of neoplastic and non-neoplastic lesions.

Uterine leiomyomas (commonly called fibroids) are perhaps the most common tumor in women ${ }^{1}$. These benign tumors of smooth muscles occur in 20-30\% females of reproductive age group ${ }^{2}$ and tend to be symptomatic. Their growth is considered to be dependent upon estrogens excess ${ }^{3}$ as leiomyomas contain more estrogen receptors than normal myometrium $^{4,5}$ and they usually regress after menopause. They are asymptomatic in more than 50\% of cases, the most important clinical manifestation is menorrhagia (in 30\% of cases), Dysmenorrhoea, abdominal pain, mass, pressure symptoms, infertility and repeated miscarriages may be the presenting symptoms ${ }^{6}$. So many times these tumours remain undiagnosed. Fibroids constitute a major public health cost to the community in terms of outpatient attendances and hospital costs for surgery of this disease ${ }^{7}$.

However, very little work has been done on their epidemiology in this part of country. So major public health cost is still not known. Another 
common frequently found entity is adenomyosis. Presence of this entity eludes the physician and commonly it is not diagnosed clinically. It is a diagnosis of histopathology and patient often present with menorrhagia and dysmenorrhoea. The histological frequency of adenomyosis varies from $5-70 \% .^{8}$

The primary malignant lesions like leiomyosarcoma are though not so common but may present like benign leiomyoma clinically. So microscopic evaluation is very essential to make a proper diagnosis and care should be taken on differentiating it from atypical leiomyoma.

Histopathology has an immense importance in the documentation of myometrial lesions, tumors and their grading accurately. The present study will try to focus on proper documentation of lesions of myometrium of uterus of the entire hysterectomy specimens.

\section{Methodology}

Patients of age groups, who were provisionally diagnosed in the outpatient department or indoors of Assam Medical College and Hospital, Dibrugarh, by taking careful history and proper clinical examination, will be included. The cases will be taken irrespective of sex, caste, religion, duration of illness and severity of conditions. The cases were then subjected to blood, radiological examinations followed by histopathological examination. After the patients were admitted, the usual procedures of recording the necessary particulars were done. The received tissue is checked for the particulars of the patient, record is maintained, labelled and then processed and stained as per the routine procedure of the department. Institutional ethical committee clearance was taken to carry out the study.

\section{Results and Observation}

Study was done on the entire hysterectomy and myomectomy specimen received from July 2012 to June 2013 in the Department of Pathology, Assam Medical College \& Hospital, Dibrugarh, Assam.

During this one year study period, 2632 specimens were received for histopathological examination in the Department, out of which 345 were hysterectomy specimens which constituted $13.10 \%$. Out of 345 cases, the study includes 104 cases which are histopathologically proved myometrial lesions.

Patients who underwent hysterectomies and myomectomies were between 2nd and 7th decade of life. Youngest was 21 years old and the oldest was 75 years old. Majority of the patients were between $31-40$ years accounting to $44.92 \%$. The most of the cases diagnosed clinically in the present study were prolapse constituting 114 patients (33.04\%) followed by dysfunctional uterine bleeding in 85 patients $(24.63 \%)$. Fibroids in 60 patients (17.39\%), and only 13 patients $(3.76 \%)$ were diagnosed as adenomyosis. Menorrhagia was found to be the commonest presenting symptom seen in 109 patients $(31.59 \%)$, followed by white discharge per vagina in 65 patients $(18.80 \%)$. Rests were of mass per vagina, pain abdomen dysmenorrhoea are one of the commonest presentations. Out of 345 patients studied, 343patients (99.42\%) were parous and only 2 patients $(0.57 \%)$ were nulliparae. Parity of the patients ranged from 1-5.

\section{Morphology of the Uterus}

Total 221 cases $(64.05 \%)$ were of normal in size, 77 cases $(22.31 \%)$ slightly enlarged, 23 cases $(6.66 \%)$ bulky and 24 cases $(6.95 \%)$ shows atrophied uterus. Among 345 uteri studied, coarse trabecular appearance was seen in 137 patients(39.71\%) which was commonest followed by well-defined grey white in 41 patients $(11.88 \%)$, coarse trabecular and grey white whorled in 27 patients $(7.82 \%)$ and illdefined mass seen only in 1 case $(0.28 \%)$. Whereas in 136 cases, the cut section morphology was unremarkable constituting $39.42 \%$.

Myometrial invasion by tumours was seen in 3 hysterectomy specimens, in the form of areas of haemorrhage and necrosis.

\section{Histopathology}

Histologically non-neoplastic lesions in the form of adenomyosis was seen in 31 cases $(8.98 \%)$

Neoplastic lesion was diagnosed in 73 cases $(21.15 \%)$ of the 345 specimens studied. Out of which 60 cases $(17.39 \%)$ were only leiomyoma and 
10 cases of leiomyoma was associated with adenomyosis constituting $2.89 \%$.

Malignant lesions seen only in 3 cases constituting $0.86 \%$ and all were secondary lesions. All the secondary lesions were diagnosed histologically endometrial carcinoma. No primary malignant lesion is seen in the present study.

\section{Non Neoplastic Lesion}

\section{Adenomyosis}

Adenomyosis was diagnosed in 31 cases out of 345 specimens and constitute $8.98 \%$.

Age

Adenomyosis was found in the age group of 20 to 50 years in the present study. Most of the cases were seen in the 3rd decade of life accounting 20 cases $(64.51 \%)$ out of the total 31 cases. Only one case was seen in the 5 th decade.

\section{Parity}

All the 31 cases of adenomyosis were seen in parous women. The Parity ranges from 1-4. Most common clinical feature of adenomyosis in the present study was menorrhagia accounting 18 cases (58.06\%) out of 31 cases. Second most common presentation was dysmenorrhoea accounting 7 cases $(22.58 \%)$. Menorrhagia i.e. found to be the predominant clinical feature in this study $(58.06 \%)$. Gross Features of Uterus with Adenomyosis:

Most of the uteri studied were normal in size accounting 26 cases $(83.87 \%)$ and 5 cases $(16.12 \%$ ) were bulky in size.

\section{Associated Pathology}

Most common associated pathology was found to be leiomyoma accounting 10 cases $(32.25 \%)$.

\section{Neoplastic Lesions of the Myometrium}

The neoplastic lesions were diagnosed in 73 cases $(21.15 \%)$ of the 345 specimens studied. Benign tumour was diagnosed in 70 cases and all of the benign tumours were leiomyomas.

\section{Leiomyoma}

Leiomyoma constitute 70 cases $(20.28 \%)$ in the present study. Out of this 10 Cases (2.89\%) were associated with adenomyosis. In the present study leiomyoma were seen in the age group of 21 to 60 years. Highest percentage of occurrence was observed in the age group of 31 to 40 years i.e. 34 cases constituting $48.57 \%$, followed by 25 cases $(35.71 \%)$ in 5 th decade, 8 cases $(11.42 \%)$ in 2 nd decade and only 3 cases $(4.28 \%$ ) seen in 6th decade.

\section{Parity}

In the present study, majority of leiomyomas were seen in parous women i.e. 68 cases $(97.14 \%)$, and only 2 cases $(2.85 \%)$ were nulliparous. Highest cases seen in para 2 with 36 cases accounting for $51.42 \%$ out of the total 70 leiomyomas.

\section{Symptoms of Leiomyoma}

Menorrhagia was the commonest symptom constituting $41.42 \%$, followed by dysmenorrhea $12.85 \%$, pain abdomen $8.57 \%$.

\section{Gross Features}

In the present study of 70 leiomyomas, 56 were bulky, 11 were normal and only 3 were atrophied. Cut section of 60 leiomyomas showed grey white whorled appearance and 10 leiomyomas show coarse trabecular

\section{Location}

Here, 49 cases were intramural with 43 being single and 6 being multiple. Subserosal myomas account for 12 cases and 8 were single and 4 were multiple. Sub mucosal myoma accounts only 9 cases and all were single in presentation. Out of 70 of leiomyomas, $60(85.71 \%)$ were single and 10 (14.28\%) were multiple \& grey white whorled appearance.

\section{Size of Leiomyomas}

In the present study, sub mucosal myoma varies from few $\mathrm{mm}$ to maximum $4 \mathrm{~cm}$ in diameter. Intramural myoma ranges from few $\mathrm{mm}$ to $7 \mathrm{~cm}$ in diameter and sub serosal myoma ranges from few $\mathrm{mm}$ to $11 \mathrm{~cm}$ in diameter.Highest dimension of the lesion measured in this study was $11 \times 8 \times 6 \mathrm{~cm}$.

\section{Histological Features of Leiomyoma}

In this study 60 cases $(85.71 \%)$ were typical leiomyomas characterised by whorled, anastomosing fascicles of uniform fusiform smooth muscle cells. The spindle-shaped cells have indistinct borders and abundant fibrillar eosinophilic cytoplasm. Nuclei is elongated with blunt or tapered ends, and have finely dispersed chromatin and small nucleoli. MF usually are infrequent. 


\section{JMSCR VoI||05||Issue||07||Page 25215-25223||July}

Secondary changes seen in 10 cases $(14.28 \%)$. And 3 variants of leiomyoma namely cellular (3 cases), atypical (2 case), and epithelioid with clear cell variant (1 case), were seen.

\section{Degenerative Changes in Leiomyoma}

10 cases showed degenerative changes out of the 70 cases of leiomyoma. Hyaline degeneration was found to be the most common degeneration constitutes 8 cases $(11.42 \%)$

\section{Variants of Leiomyoma}

Six cases $(8.57 \%)$ of variant leiomyomas namely cellular, atypical and epithelioid variant were detected.

Cellular leiomyoma cases were 3 in number. All the patient were on 3rd decade of life. Histopathological study showed regular, elongated and fusiform cells having scanty eosinophilic cytoplasm. Occasional mitotic figure seen.

Atypical leiomyoma was found in two cases. One patient was on her 4th decade and presented with pain abdomen another one with prolapse. Histology showed cells having moderate to severe atypia, mitotic index $<10 \mathrm{MF} / 10 \mathrm{HPF}$ without necrosis. Epithelioid leiomyoma accounts only one case and seen in women in her 5 th decade. Histology showed round to polygonal cells with clear cytoplasm and some areas showed leiomyoblastoma component.

Endometrial Changes in Leiomyomatous Uterus:

Endometrial change was studied in 70 cases of leiomyoma and out of that proliferative change was found to be highest i.e. 50 cases constituting $71.42 \%$ followed by secretory change in 13 cases $(18.57 \%$ ) and 1 case (1.42)of endometrial hyperplasia observed.

\section{Associated Pathology in Leiomyomas}

Most common associated pathology was adenomyosis 10 cases (14.28\%).

\section{Malignant tumours of myometrium:}

In the present study no primary malignant tumour of myometrium encountered. Only 3 cases of secondary malignant tumours invading into the myometrium were found and all were endometrial carcinoma

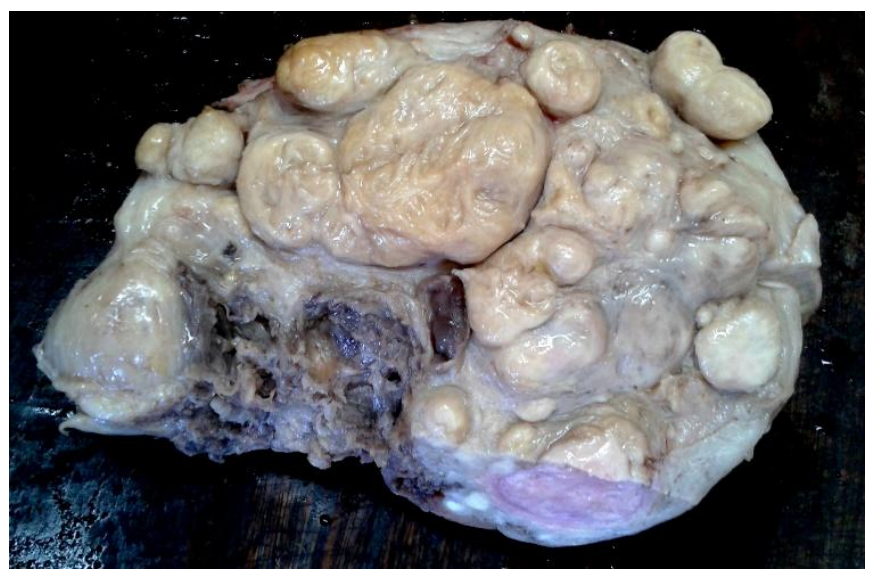

Fig 1 Multiple Subserosal Leiomyoma

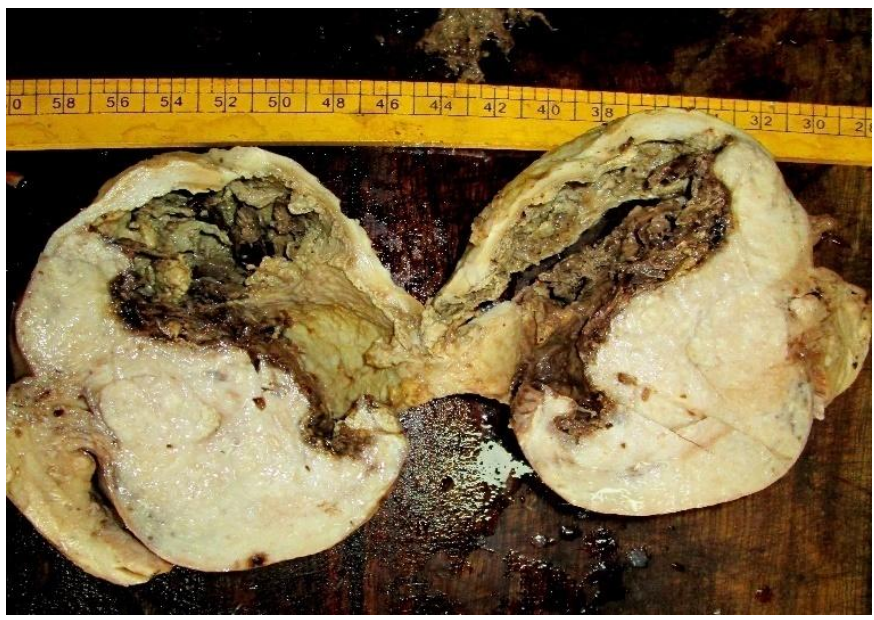

Fig 2: Leiomyoma With Degeneration

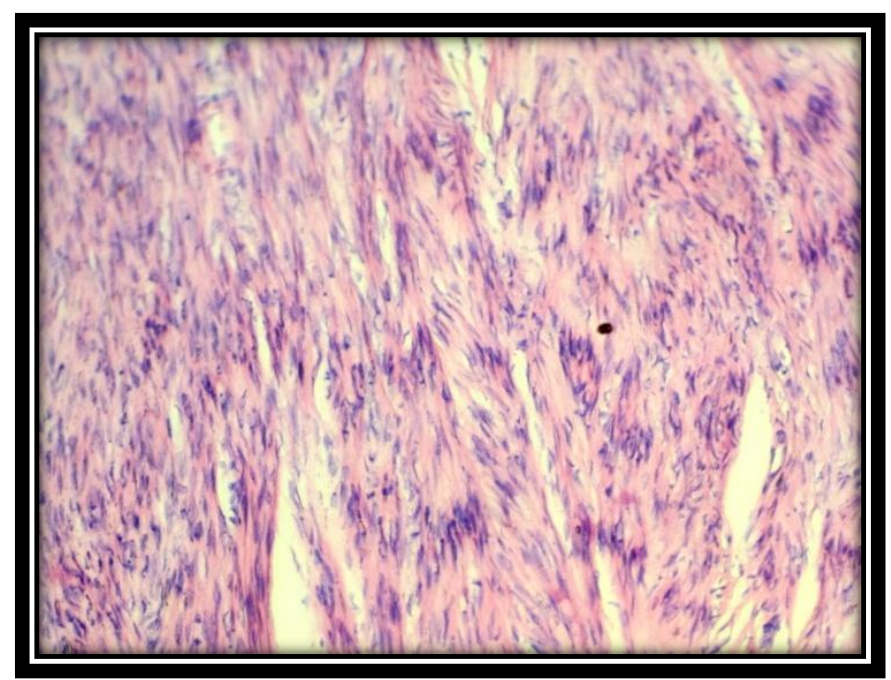

Fig 3: Leiomyoma with Hyaline Degeneration 


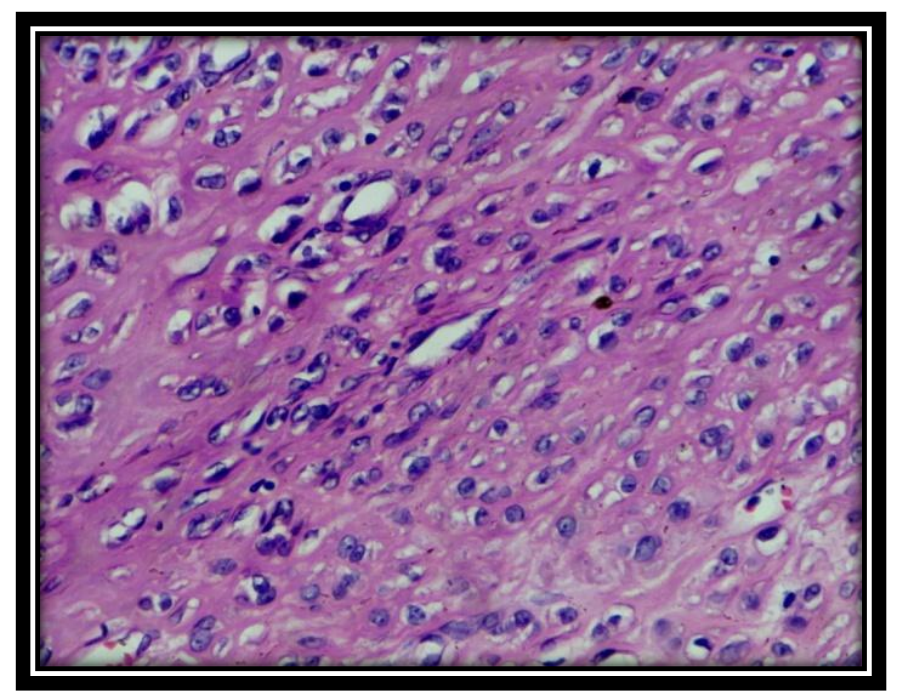

Fig 4: Epithelioid Leiomyoma

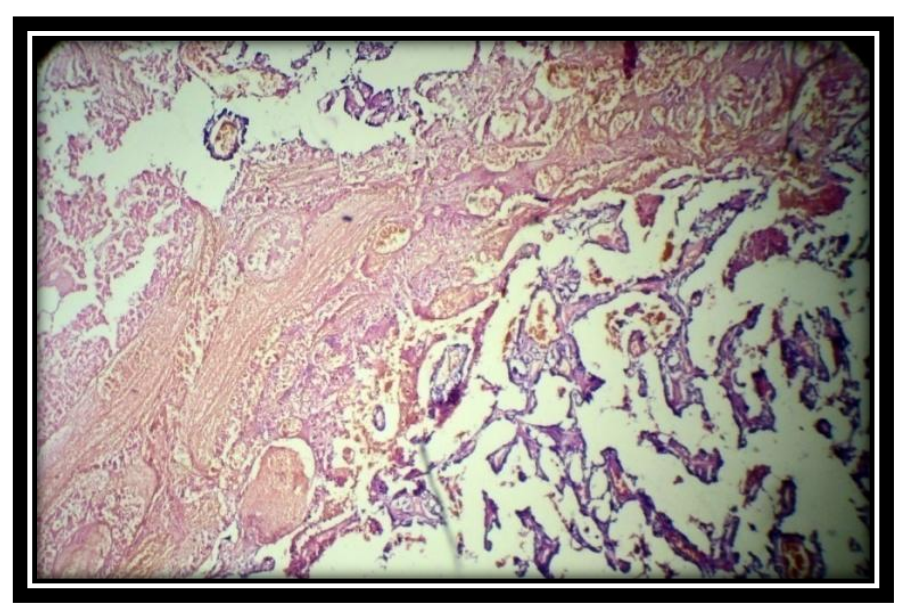

Fig 5 Endometrial Carcinoma Invading Myometrium

\section{Discussion}

In the present study since July 2012 to June 2013, out of the total 2632 specimen received, 345 specimens were hysterectomy cases. Majority of the patient studied were under the age group of 31-40 years $(44.92 \%)$ and only one case seen in the 7 th decade $(0.28 \%)$.

The preoperative diagnosis showed prolapse to be the commonest one (33.04\%), followed by dysfunctional uterine bleeding $(24.63 \%)$ and adenomyosis was diagnosed only in (3.76\%) clinically. Majority of the patients were found to be parous $(99.42 \%)$ and only 2 patients were nulliparous $(0.57 \%)$ and most of the patient presented with menorrhagia $(31.59 \%)$ followed by white discharge $(18.80 \%)$.
In this study myometrial lesions were classified and studied under non neoplastic and neoplastic lesions. Adenomyosis was found to be the most common non neoplastic condition $(8.98 \%)$ and neoplastic condition shows leiomyoma as the most common benign tumour (20.28\%) and only 3 cases of secondary malignant infiltration into myometrium seen $(0.86 \%)$. No primary malignant tumour of myometrium seen in the present study.

\section{Non Neoplastic Lesion}

\section{Adenomyosis}

In the present study, adenomyosis was found in 31 cases $(8.98 \%)$ which correlate with the study of Molitor et $\mathrm{al}^{9}$ where adenomyosis comprise $8.80 \%$ of all the cases studied. In contrast the study of Pentikilkku et $\mathrm{al}^{10}$ shows adenomyosis in $13.20 \%$ of cases.

The incidence of adenomyosis varies widely in various literatures. Although many reasons for these marked variations have been advanced no satisfactory answer so far has been found.

Age

In the present study, highest no of cases seen in the age group of 31-40 years (64.51\%) which correlate with the study of Aziz et $\mathrm{al}^{11}(70.80 \%)$ and Mollitoret $\mathrm{al}^{9}$ (76.20\%) respectively.

\section{Parity}

In our study, all the 31 cases of adenomyosis were seen in parous women. Similarly, the study of Molitor $^{9}$ and Paolo Vercillini ${ }^{12}$ also showed higher incidence of adenomyosis in multiparous women.

\section{Clinical Feature}

Most common clinical feature of adenomyosis in the present study was menorrhagia accounting 18 cases $(58.06 \%)$ out of 31 cases. Second most common presentation was dysmenorrhoea 07 cases $(22.58 \%)$. Similarly the study of Mollitor et $\mathrm{al}^{9}$ found menorrhagia in $63.00 \%$ and dysmenorrhoea in $21.30 \%$ of all the cases studied.

\section{Gross Features of Uterus with Adenomyosis}

Most of the uteri studied were normal in size accounting 26 cases $(83.87 \%)$ and 5 cases $(16.12 \%)$ were bulky in size. In the study of Molitor et $\mathrm{al}^{9}$ 
significant uterine enlargement due to adenomyosis was found in $25.00 \%$ of the cases. Most of the cases were normal in size in his study also.

\section{Endometrial changes in Adenomyosis}

In the present study, proliferative endometrial changes accounts highest percentage (80.64\%) followed by secretory phase $(16.12 \%)$ and one case of endometrial hyperplasia was seen (3.22\%). Similarly, Mollitor9 found proliferative, secretory and endometrial hyperplasia in $40.00 \%, 32.40 \%$ and $6.00 \%$. Thus the study of Mollitor9 also noted a highest incidence of proliferative endometrium in his study of 281 cases.

\section{Associated Pathology}

In the present study, Most common associated pathology was found to be leiomyoma accounting 10 cases $(32.25 \%)$ followed by follicular cyst in 6 cases $(19.35 \%)$ The association of leiomyoma with adenomyosis correlates with the study of Mollitor ${ }^{9}$ (38.40\%) \& McCausland ${ }^{13}$ (55.00\%).

However, the various pathology associated with adenomyosis is nonspecific and probably related to associated diseases.

\section{Neoplastic Lesions of the Myometrium}

The neoplastic lesions were diagnosed in 73 cases $(21.15 \%)$ of the 345 specimens studied. Benign tumour was diagnosed in 70 cases and all of the benign tumours were leiomyomas. And the rest 3 cases were endometrial carcinoma infiltrating into the myometrium.

\section{Leiomyoma}

In the present study, Leiomyoma constitute 70 cases $(20.28 \%)$.

The study of Nayak et $\mathrm{al}^{14}$ and Ezeama CO et $\mathrm{al}^{15}$ found leiomyoma in $37.00 \%$ and $10.7 \%$ of cases respectively which was comparable with the present study. However Reddy et $\mathrm{al}^{16}$ found leiomyoma only in $3.19 \%$ of cases. Thus the incidence of leiomyoma varies among various studies.

\section{Age}

In the present study leiomyoma were seen in the age group of 21-60 years. The highest no of cases were in age group 31 to 40 years $(48.57 \%)$ and the least cases were seen in the 6th decades.

Similarly the study of Ezeama CO et $\mathrm{al}^{15}$ found majority of cases in age group of 30-44 years $(75.60 \%) \&$ the least presentation in age group 5054 years.

The present finding also correlates well with the observations made by Reddy \& Malathy16 and Rosario Pinto studies ${ }^{17}$ where the highest no of leiomyomas were in the age group of 31-40 years. Thus from the various studies, leiomyoma was found to be most common in the reproductive age group.

\section{Parity}

In the present study, majority of leiomyomas were seen in parous women i.e. 68 cases $(97.14 \%)$, and only 2 cases $(2.85 \%)$ were nulliparous. Similarly in the study of Nayak et al ${ }^{14}$ majority of cases were multiparous $(81.08 \%)$ and $5.41 \%$ were nulliparous.

\section{Clinical Features}

In the present study Menorrhagia was the commonest symptom constituting $41.42 \%$ of all leiomyoma cases. This finding was consistent with the studies of Rosario Pinto 17 (37.90\%) and Nayak et $\mathrm{al}^{14}(40.54 \%)$ where menorrhagia was found as the commonest symptom associated with leiomyoma. Whereas it was only $16 \%$ in the study of Bhaskar Reddy \& Malathy ${ }^{15}$.

The second most common symptom associated with leiomyoma was dysmenorrhoea comprising $12.85 \%$, which correlate with the study of Nayak et $\mathrm{al}^{14}$ (13.51\%).

White discharge per vagina in the present study $(4.28 \%)$ correlate with the Reddy and Malathy ${ }^{16}$ (9.50\%).

\section{Location of Leiomyoma}

In the present study, highest no of leiomyoma were intramural $(70.00 \%)$, followed by subserosal (17.14\%) and sub mucosal (12.85\%).

The findings of location of intramural leiomyoma $(70.00 \%)$ in the present study is consistent with the study of Rosario pinto ${ }^{17}(73.50 \%) \&$ Nayak et $\mathrm{al}^{14}$ $(67.57 \%)$.

The location of sub serosal leiomyoma $(17.14 \%)$ in the present study correlate with shaw $18(15 \%)$ and 
nayak et $\mathrm{al}^{14}(10.81 \%)$ and the location of sub mucosal leiomyoma (12.85\%) that of shaw18 (10\%). In the present study the no of leiomyoma in the uterus varied from 1-12 whereas Rosario pinto ${ }^{17}$ noted a maximum no up to 14 .

\section{Histological Features of Leiomyoma}

In this study, out of seventy cases 60 cases $(85.71 \%)$ were typical leiomyomas and the rest 10 (14.28\%) cases were associated with degenerative changes.

This correlate with the study of Rosario Pinto ${ }^{17}$ where degenerative changes comprised $12.20 \%$ of all the cases studied.

In the present study various types of degenerative changes were observed and the most common degenerative change was hyaline degeneration which constitutes $11.42 \%$. Rosario pinto ${ }^{17}$ found hyaline degeneration in $8 \%$ of the cases where as Reddy \& Malathy ${ }^{16}$ observed hyaline change in all the cases of leiomyomas (100\%). None of the leiomyoma cases were associated with calcification in the present study which correlate well with various studies.

\section{Variants of Leiomyoma}

Although several histopathological variants of leiomyomas have been described in the literature, only 3 variants were encountered in the present study. There are 6 cases $(8.57 \%)$ of variant leiomyomas namely cellular, atypical and epithelioid variant.

Cellular leiomyoma cases were 3 in number. All the patient presented with menorrhagia and was on 3rd decade of life. Histopathological study showed regular, elongated and fusiform cells having scanty eosinophilic cytoplasm. Occasional mitotic figure seen.

Atypical leiomyoma was found in one case. The patient was on her 4th decade and presented with pain abdomen. Histology showed cells having moderate to severe atypia, mitotic index $<10 \mathrm{MF} / 10$ HPF without necrosis.

Epithelioid leiomyoma accounts only one case and seen in women in her 5 th decade. Histology showed round to polygonal cells with clear cytoplasm and some areas showed leiomyoblastoma component. Histopathological features of variant leiomyoma in the present study were similar to the features mentioned by various authors.

\section{Endometrial changes in Leiomyomatous Uterus}

Endometrial change was studied in 70 cases of leiomyoma and out of that proliferative change was found to be highest i.e. 50 cases constituting $71.42 \%$ followed by secretory change in 13 cases $(18.57 \%)$ and 1 case $(1.42 \%)$ of endometrial hyperplasia observed.

Similarly the incidence of proliferative and secretory changes was found in $51.10 \%$ and $17.50 \%$ cases respectively in the study of Rosario Pinto 17. But the incidence of endometrial hyperplasia (20.40\%) was found significantly higher in his study.

\section{Associated Pathology in Leiomyoma}

In the present study, adenomyosis was the commonest associated pathology comprising $14.28 \%$ which correlate with the study of Rosario Pinto17 (11.30\%).

While most of the cases of leiomyoma (74.28\%) were not associated with any pathology.

\section{Malignant Tumors of Myometrium}

In the present study, no primary malignant tumour of myometrium was encountered. Various studies in the literature reported very low incidence of leiomyosarcoma. Leiomyosarcoma comprised $0.075 \%$ and $<1.0 \%$ in studies of William parker et $\mathrm{al}^{19}$ and Waldmann et $\mathrm{al}^{20}$ respectively.

Only 3 cases of secondary malignant tumors invading into the myometrium were found and all were well differentiated endometrial carcinoma. Various studies suggest direct extension of endometrial carcinoma in to the myometrium. ${ }^{21,22,23}$

\section{Conclusion}

The main objective of this study was to find out the exact current status of uterine myometrial morbidity in the women of this part of country. Though uterine lesions are most commonly encountered in histopathology laboratory but a proper documentation is needed to find out the actual health cost and co current morbidity in woman of all age group. In the present study, leiomyoma was found to be the most common lesion apart from adenomyosis and majority of the cases were 
presented with menorrhagia and seen in the reproductive age group. Though immuno histochemistry and cytogenetics was not done in the present study but its role is highly solicited in difficult cases.

\section{References}

1. Lora Hedrick Ellenson, Edyta C, Pirog, The female genital tract. In Kumar, Abbas, Fausto, Aster editors, Robbins and Cotran Pathological basis of disease. 8th edition, India; ELSEVIER:2011, P.1036

2. BrandlyJP. Uterine fibroids "What every women should know, treatment choices for benign uterine conditions www.Obgyn.netaservices of Eleconcorp.

3. Benangiano G,Cronje H,Kivinen ST.Be Zoladex (goserelinacetate) and anemic patient: results of amulticentrefibroid study. Fertility and sterilityAmerJ 1996;66:223-8

4. Rein MS,BarbieriRL, Friedman AJ. Progesterone: A critical role in pathogenesis of uterinemyomas. Am J Obst Gynecol 1995;172(1)14-8.

5. Smith SK. Regulation of fibroid growth: time for a rethink? Br J Obst Gynaecol 1993;100:977-8

6. S Begum, S Khan - audit of leiomyoma uterus at khyber teaching hospitalPeshawar,J Ayub Med Coll Abbottabad,2004 ayubmed.edu.pk

7. Vollenhoven BJ, Lawrence AS, Healy DL. Uterine fibroids: A clinical review. $\mathrm{Br} \mathrm{J}$ of Obstet Gynecol. 1990 April; 97: 285-298.

8. Marc Bazot, Annie Cortez et al. Ultrasonography compared with magnetic resonance imaging for the diagnosis of adenomyosis: Correlation with histopathology. Human Reproduction. 2001; 16(11): 2427-2433.

9. Molitor John J. Adenomyosis: A clinical and pathologic appraisal. Am J Obstet Gynecol. 1971; 110(2): 275-284.

10. Kilkku P, Erkkola R and Gronnoos M. Nonspecificity of symptoms related to adenomyosis - A prospective comparative survey. Acta Obstet Gynecol Scared. 1984; 63: 229-231.

11. Ricardo Azziz. Adenomyosis: Current perspectives. Obstet \& Gynecol Clinics of North America. 1989 March; 1691): 221235.

12. Vercellin P, Parazzini F, Oldani S, Panazza $\mathrm{S}$, Bramante T, Crosignani PG. Adenomyosis at hysterectomy: A study on frequency distribution and patients characteristics. Hum Reprod. 1995 May; 10(5): 1160-1162.

13. Arthur m, McCausland. Hysteroscopic myometrial biopsy: Its use in diagnosing adenomyosis and its clinical application. Am J Obstet Gynecol. 1992; 166(6): Part-I: 1619-1628

14. Dr. Jyoti C. Nayak, Dr Vipul P. Prajapati, Dr. Kinnar S. Desai, Dr. H.R.Jadav, Dr S.M.Chaudhary, Dr. C.A.Pensi:Uterine Leiomyoma: Clinical Profile At Civil Hospital, Ahmedabad:NJIRM.2012; 3(4): 50-53

15. Ezeama CO, Ikechebelu JI, Obiechina NJ, Ezeama NN.Clinical Presentation of Uterine Fibroids in Nnewi,Nigeria: A five year Review: Annals of Medical and Health Sciences Research | July 2012 | Vol 2 | Issue 2

16. Reddy DB and Malathy PM. Fibromyoma uterus. J of Obstet \& Gynecol of India. 1963; 13: 54.

17. Pinto Rosari Y. Uterine fibromyomas. J of Obstet \& Gynecol of India. 1968; 18: 101107.

18. Howkins and Bourne. New growth of the uterus: Connective tissue tumors. In: Padubidri VG and Shirish N Daftray editors Shaw's Textbook of Gynecology. 10th Edn. New Delhi; Churchill Livingstone: 1989. P. 399-427.

19. Parker WH, Fu YS and Berck JS. Uterine sarcoma in patients operated on for presumed leiomyoma and rapidly growing 
leiomyoma. Obstet \& Gynecol. 1998; 83: 414-418

20. Waldmann J, Stachs A, Terpe H, Strophal G, Makovitzky J. Smooth muscle tumors of uterine corpus: A clinicopathologic study with immuno-histochemical aspects. Anticancer Res. 2005 May-June; 25(3A): 1559-1565.

21. Anderson MC. Female genital tract. In: Symmer SW editor. Systemic Pathology. 3" Edition. Edinburg; Churchill Livingstone: 1991. P. 284-312.

22. Hendrickson MR and kempson RL. Pure mesencymal neoplasms of the uterine corpus. In: Fox H Editors Obstetrical \& Gynecological Pathology. 4th Ed. New York; Churchill Livingstone: 1995. P. 511586.

23. Zaloudek C, Norris M. Mesenchymal tumors of the uterus. In: Kurman RJ ed. Blaustein's Pathology of the female genital tract. 2ndEd. New York. Springer-Verlag: 1982. P. 235392. 